\title{
Plasma-Assisted Titanium Dioxide Wrinkle Resistant Treatment of Cotton Fabric
}

\author{
C. W. Kan
}

\begin{abstract}
Titanium dioxide $\left(\mathrm{TiO}_{2}\right)$ has been found feasible for improving the wrinkle resistant of cotton fabric. In this paper, plasma treatment was used as a pretreatment process to enhance the application of $\mathrm{TiO}_{2}$ in wrinkle resistant treatment of cotton fabric. The relationship between plasma pretreatment process parameters including (i) treatment speed, (ii) oxygen flow rate; and (iii) jet distance were studied through orthogonal array testing strategy (OATS). Based on the OATS, the optimum condition for plasma pretreatment of cotton fabric before $0.2 \% \quad \mathrm{TiO}_{2}$ treatment could be obtained and also their relative importance can be found. The optimum condition was: (i) treatment speed $=15 \mathrm{~mm} / \mathrm{s}$; (ii) oxygen flow rate $=0.3 \mathrm{~L} / \mathrm{min}$. and (iii) jet distance $=5 \mathrm{~mm}$ and the order of importance was oxygen flow rate followed by jet distance and treatment speed.
\end{abstract}

Index Terms-Wrinkle resistant, titanium dioxide, plasma, cotton fabric.

\section{INTRODUCTION}

In previous studies [1]-[4], titanium dioxide $\left(\mathrm{TiO}_{2}\right)$ were found to have efficiency for improving wrinkle resistant property of cotton fabrics and enhancing the final performance with minimized side effects [1]-[4]. However, there is lack of study regarding the effect of $\mathrm{TiO}_{2}$ itself on wrinkle resistant property of cotton fabric. The interaction between $\mathrm{TiO}_{2}$ and cotton is mainly appeared in fibre surface. Thus, the fibre structure such as roughness would play an important role for $\mathrm{TiO}_{2}$ to be functionalized. In this study, plasma treatment will be used for changing the roughness of cotton fabric surface. The changes in roughness of cotton fabric surface caused by plasma pre-treatment facilitate the attachment of $\mathrm{TiO}_{2}$ particles on the fabric surface. [5]-[8]. In the plasma, the highly energetic active species produced in plasma cause etching effect to alter surface characteristics of cotton fabric [9]. The plasma treatment incorporates a large variety of chemically active functional groups and it roughens the material surface [6], [10]-[13]. Since plasma treatment process parameters are inter-related, effects of process parameters such as treatment speed, oxygen flow rate and jet distance are studied through orthogonal array testing strategy (OATS). Based on the results of OATS, the optimum condition for plasma pretreatment of cotton fabric before $\mathrm{TiO}_{2}$ treatment could be obtained and also their relative importance can be found.

Manuscript received November 17, 2013; revised January 6, 2014. This work was supported in part by the Innovation and technology Fund, Innovation and technology Commission, The Government of the Hong Kong Special Administrative Region (ITS/029/12).

C. W. Kan is with the Institute of Textiles and Clothing, The Hong Kong Polytechnic University, Hung Hom, Kowloon, Hong Kong (e-mail: tccwk@polyu.edu.hk).

\section{EXPERIMENTAL}

\section{A. Materials}

$100 \%$ semi-bleached twill cotton fabric of size $30 \mathrm{~cm} \times 30$ $\mathrm{cm}$ was used. $\mathrm{TiO}_{2}$ particles with average diameter of $2 \mu \mathrm{m}$ were used.

\section{B. Plasma Pretreatment}

Plasma pretreatment of cotton fabric wa s carried out by an atmospheric pressure plasma jet (Surfx Technologies, USA). The atmospheric pressure plasma jet can generate stable discharge with radio frequency of $13.56 \mathrm{MHz}$. Helium and oxygen were used as carrier and reactive gases, respectively. In order to determine optimum plasma pre-treatment conditions, an orthogonal array testing strategy (OATS) technique was used. Three variables: (i) treatment time (expressed as treatment speed), (ii) oxygen flow rate and (iii) jet distance, were studied and three levels were set for each variable. Details of the experimental arrangements were summarized in Table I. Fig. 1 shows the set-up for plasma treatment.

\begin{tabular}{cccc}
\multicolumn{4}{c}{ TABLE I: EXPERIMENTAL ARRANGEMENT } \\
\hline $\begin{array}{c}\text { Test } \\
\text { run }\end{array}$ & $\begin{array}{c}\text { Treatment speed } \\
(\mathrm{mm} / \mathrm{s})\end{array}$ & $\begin{array}{c}\text { Oxygen flow rate } \\
(\mathrm{L} / \mathrm{min})\end{array}$ & $\begin{array}{c}\text { Jet distance } \\
(\mathrm{mm})\end{array}$ \\
\hline 1 & 30 & 0.1 & 1 \\
2 & 30 & 0.2 & 3 \\
3 & 30 & 0.3 & 5 \\
4 & 15 & 0.1 & 3 \\
5 & 15 & 0.2 & 5 \\
6 & 15 & 0.3 & 1 \\
7 & 5 & 0.1 & 5 \\
8 & 5 & 0.2 & 1 \\
9 & 5 & 0.3 & 3 \\
\hline
\end{tabular}

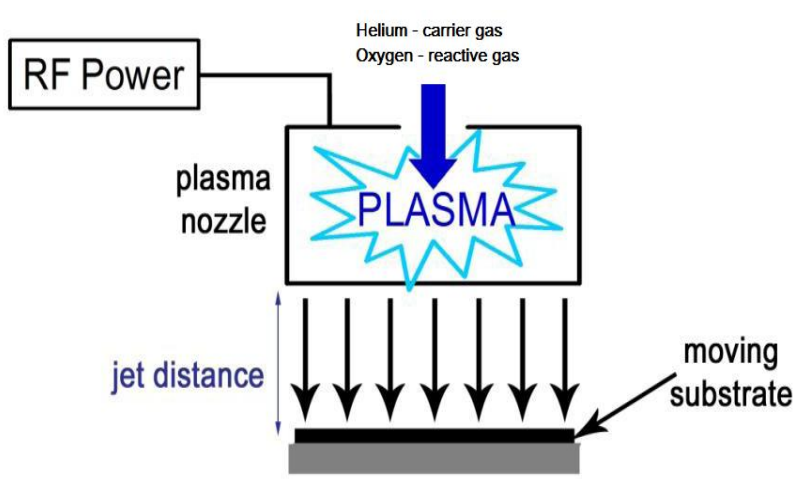

Fig. 1. Schematic diagram of plasma treatment.

\section{C. $\mathrm{TiO}_{2}$ Pad-Dry-Cure Treatment}

After plasma pretreatment, the cotton fabrics were dipped 
and padded with $0.2 \% \mathrm{TiO}_{2}$ (dispersed in $10 \%$ Matexil DN-VL dispersing agent) until wet pick up of $70 \%$ was achieved at room temperature. The specimens were then dried at $100^{\circ} \mathrm{C}$ for 5 minutes and cured at $150^{\circ} \mathrm{C}$ for 2 minutes. Finally, the fabrics were conditioned at $21 \pm 1^{\circ} \mathrm{C}$ and $65 \pm 2 \%$ relative humidity for 24 hours before evaluation.

\section{Conventional Wrinkle Resistant Treatment}

One cotton fabric, for control purpose, was padded with $5 \%$ commercial self-catalyzing crosslinking agent (Dimethylol dihydroxyethyleneurea, DMDHEU) until a pick-up of $70 \%$ was achieved at room temperature. Then the padded fabric was dried completely at $100^{\circ} \mathrm{C}$ and was cured subsequently at $150^{\circ} \mathrm{C}$ for 2 minutes. Finally, the fabrics were conditioned at $21 \pm 1^{\circ} \mathrm{C}$ and $65 \pm 2 \%$ relative humidity for 24 hours before evaluation. 24 hours before any further treatment.

\section{E. Wrinkle Resistant Evaluation}

The wrinkle resistant property of cotton fabric was evaluated using wrinkle recovery angle (WRA) according to AATCC Test Method 66-2008.

\section{RESULTS AND DISCUSSION}

\section{A. Optimum Condition for Plasma Pretreatment}

Table II shows the WRA results of plasma pretreated cotton fabric followed by $0.2 \% \mathrm{TiO}_{2}$ treatment. It was noted that WRAs of the cotton fabrics varies depending on the plasma pretreatment process parameters. Based on the OATS the optimum condition for the plasma pretreatment is $15 \mathrm{~mm} / \mathrm{s}$ speed, $0.3 \mathrm{~L} / \mathrm{min}$ oxygen flow rate and $5 \mathrm{~mm}$ jet distance. Table II also shows that oxygen flow rate was the most dominant factor for effectiveness of the plasma treatment, followed by jet substrate distance and then by treatment speed.

In this study, it is noted that plasma pretreatment could enhance wrinkle resistant property with the use of $0.2 \% \mathrm{TiO}_{2}$. This phenomenon could be explained by the etching effect on the fabric surface caused by plasma pretreatment which provides a new pathway for the finishing agent to enter into the fibre resulting in increasing the WRA. The presence of $\mathrm{TiO}_{2}$ particles in the fibre restricts the molecular movement of cellulose.

Table II shows that plasma pretreatment at $15 \mathrm{~mm} / \mathrm{s}$ treatment speed demonstrated the best balance between enhancement of WRA and minimization of fiber damage, irrespective of the concentration of $\mathrm{TiO}_{2}$ in the subsequent treatment as shown in Fig. 2. This speed of plasma treatment provides enough time for the substrate to interact with active species produced in plasma gases. When the treatment speed was set at $5 \mathrm{~mm} / \mathrm{s}$, the concentration of active species in the plasma accumulating on the surface of the cotton fiber will be increased. Once the concentration of the active species increased to a critical level, the interaction between the active plasma species and the cotton fiber surface would be saturated As a result, the effect is not good when compared with $15 \mathrm{~mm} / \mathrm{s}$. In case of treatment speed of $30 \mathrm{~mm} / \mathrm{s}$, the cotton fabric is moving in the fastest speed which means the treatment time is the shortest. When the plasma generates the active species, it should have sufficient for the actives species to interact with the cotton fiber. If the treatment time is too short, the surface reaction due to the active species in plasma would be minimized. Hence, treatment speed of $30 \mathrm{~mm} / \mathrm{s}$ gives the least effect in plasma treatment.

TABLE II: OPTIMIZATION OF PLASMA PRE-TREATED OF COTTON FABRIC FOLLOWED BY $0.2 \% \mathrm{TIO}_{2}$ TREATMENT

\begin{tabular}{|c|c|c|c|c|}
\hline $\begin{array}{l}\text { Test } \\
\text { run }\end{array}$ & $\begin{array}{l}\text { Treatment speed } \\
(\mathrm{mm} / \mathrm{s})\end{array}$ & $\begin{array}{l}\text { Oxygen flow rate } \\
(\mathrm{L} / \mathrm{min})\end{array}$ & $\begin{array}{l}\text { Jet distance } \\
(\mathrm{mm})\end{array}$ & WRA $\left(^{\circ}\right)$ \\
\hline 1 & 30 & 0.1 & 1 & 80.9 \\
\hline 2 & 30 & 0.2 & 3 & 83.2 \\
\hline 3 & 30 & 0.3 & 5 & 91.3 \\
\hline 4 & 15 & 0.1 & 3 & 86.6 \\
\hline 5 & 15 & 0.2 & 5 & 88.3 \\
\hline 6 & 15 & 0.3 & 1 & 88.3 \\
\hline 7 & 5 & 0.1 & 5 & 84.5 \\
\hline 8 & 5 & 0.2 & 1 & 87.1 \\
\hline \multirow[t]{2}{*}{9} & 5 & 0.3 & 3 & 86.7 \\
\hline & & Treatment speed & $\begin{array}{l}\text { Oxygen flow } \\
\text { rate }\end{array}$ & $\begin{array}{c}\text { Jet } \\
\text { distance }\end{array}$ \\
\hline & $\sum \mathrm{I}$ & 255.4 & 252.0 & 256.3 \\
\hline & $\sum \mathrm{II}$ & 263.2 & 258.6 & 256.5 \\
\hline & $\sum$ III & 258.3 & 266.3 & 264.1 \\
\hline \multicolumn{2}{|c|}{$\begin{array}{l}\text { Dominating Level } \\
\text { parameters }\end{array}$} & $15 \mathrm{~mm} / \mathrm{s}$ & $0.3 \mathrm{~L} / \mathrm{min}$ & $5 \mathrm{~mm}$ \\
\hline & Difference & 7.8 & 14.3 & 7.8 \\
\hline
\end{tabular}

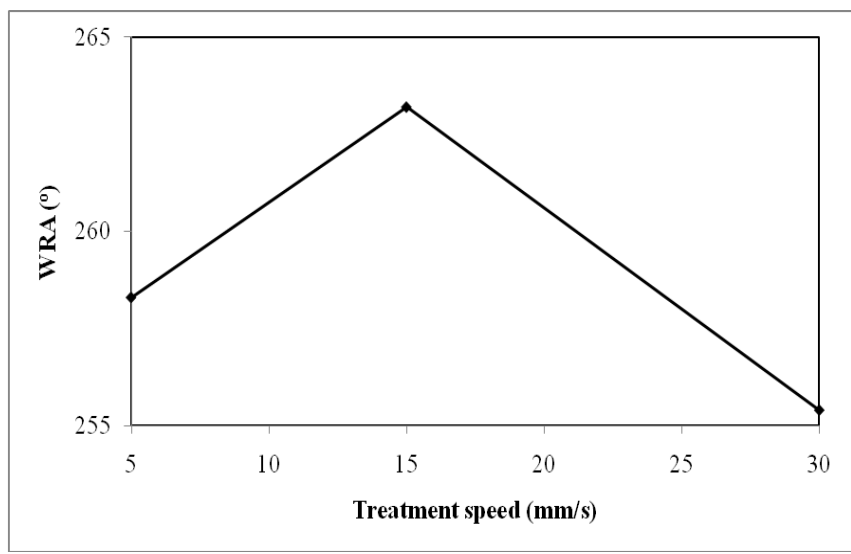

Fig. 2. The effect of treatment speed in plasma pretreatment on the results of WRA.

In addition, oxygen flow rate affects the amount of oxygen to be supplied for the plasma treatment. Generally speaking, the higher the oxygen flow rate, the more will be the oxygen supplied for the plasma treatment. In this study, the increase in oxygen flow rate speeds up the production of active species which enhances surface modification of fabrics as shown in Fig. 3. High oxygen flow rate $(0.3 \mathrm{~L} / \mathrm{min}$.) carries more concentrated active species causing a severe sputtering or etching effect that alters the fabric surface characteristics. When plasma pretreated fabrics are subjected to $\mathrm{TiO}_{2}$ treatment, $\mathrm{TiO}_{2}$ particles fill up the roughened cotton fiber surface which restricts molecular movement of cellulose. Hence, oxygen flow rate is the dominating factor in enhancing the effectiveness of plasma pre-treatment for improved WRA of cotton fabrics. The results show that $0.3 \mathrm{~L} / \mathrm{min}$ oxygen flow rate is the best condition for plasma pre-treatment. 


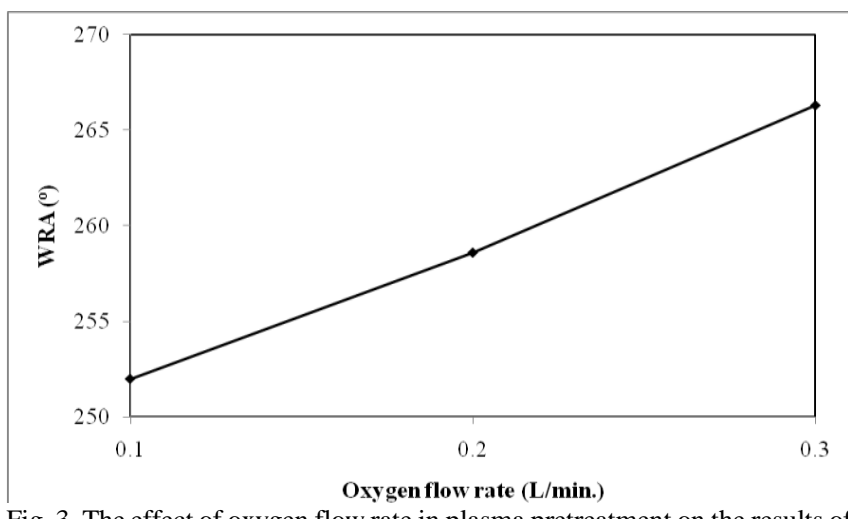

Fig. 3. The effect of oxygen flow rate in plasma pretreatment on the results of WRA.

In case of jet distance, it is necessary to select a suitable jet distance in order to achieve the best plasma effect. In this study, when the distance between the plasma jet nozzle and the substrate surface was far enough, i.e. $5 \mathrm{~mm}$, plasma species from the nozzle effectively flow over the fabric surface, demonstrating that it was the best treatment for enhancing the WRA of the fabric (Fig. 4). However, when the distance between the plasma jet nozzle was too small, the flow of oxygen gas from the nozzle was almost blocked by the fabric and the oxygen gas could only be bounced off the surface and flew out in a more parallel to the fabric surface direction, which greatly recued the effectiveness of the treatment [5]. On the hand, when the distance was too long, the velocity and the activity of the active species in the plasma jet greatly decreased when reaching the surface of the fabric and thus was not effective either [5]. In addition, when the jet distance was too long, the active species in plasma would collide with the surrounding air molecule and hence reduced their reactivity.

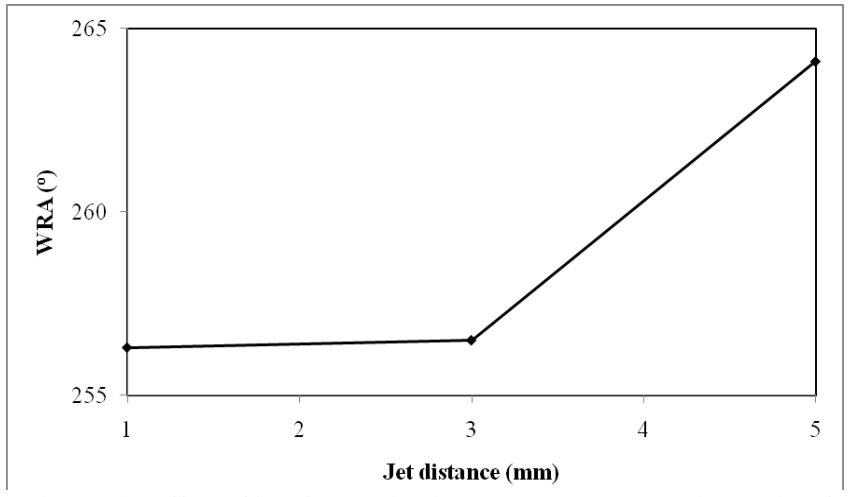

Fig. 4. The effect of jet distance in plasma pretreatment on the results of WRA.

\section{B. Comparison of WRA}

Table III provides WRA values of cotton fabrics treated under different conditions. Although plasma pre-treatment itself could enhance wrinkle resistant property of cotton fiber, further addition of $\mathrm{TiO}_{2}$ could achieve a better result. $\mathrm{TiO}_{2}$ could fill up the plasma induced roughened fiber surface which restricts molecular movement of the cellulose during the wrinkling process. In addition, a conventional wrinkle resistant treatment using crosslinking agent of DMDHEU was applied to the cotton fiber. Although the DMDHEU treatment could significantly improve the wrinkle resistant property of cotton fiber, the result is not good when compared with plasma and plasma- $\mathrm{TiO}_{2}$ treatments.

TABLE III: WRA VALUES OF COTTON FABRICS TREATED UNDER DIFFERENT CONDITIONS

\begin{tabular}{ccccc}
\hline Sample & $\begin{array}{c}\text { Treatment } \\
\text { speed } \\
(\mathrm{mm} / \mathrm{s})\end{array}$ & $\begin{array}{c}\text { Oxygen } \\
\text { flow rate } \\
(\mathrm{L} / \mathrm{min} .)\end{array}$ & $\begin{array}{c}\text { Jet-to-substrate } \\
\text { distance }(\mathrm{mm})\end{array}$ & $\begin{array}{c}\text { WRA } \\
\left({ }^{\circ}\right)\end{array}$ \\
\hline Untreated & 0 & 0 & 0 & 74.6 \\
$\begin{array}{c}\text { Conventional } \\
\text { wrinkle resistant } \\
\text { treatment with } \\
\text { DMDHEU } \\
\begin{array}{c}\text { Plasma pretreated } \\
\text { only }\end{array}\end{array}$ & 15 & 0.3 & 5 & 92.3 \\
$\begin{array}{c}\text { Plasma-pretreated } \\
\text { and 0.2\% TiO } 2 \\
\text { post-treated }\end{array}$ & 15 & 0.3 & 5 & 101.4 \\
\hline
\end{tabular}

\section{CONCLUSION}

In this paper, optimization of plasma pretreatment for enhancing wrinkle resistant property of cotton fibre was investigated with the OATS. The process parameters were taking into consideration, the optimum condition was: 1) treatment speed $=15 \mathrm{~mm} / \mathrm{s} ; 2$ ) oxygen flow rate $=0.3 \mathrm{~L} / \mathrm{min}$. and 3) jet distance $=5 \mathrm{~mm}$. The order of importance was oxygen flow rate followed by jet distance and treatment speed. It was found that plasma pretreatment alone can improve the wrinkle-resistant property of cotton fabric. Although single plasma pretreatment could improve wrinkle resistant property when compared with conventional DMDHEU treated cotton fabric, post-treatment with $0.2 \% \mathrm{TiO}_{2}$ could further enhance wrinkle resistant property.

\section{ACKNOWLEDGMENT}

This is a research project funded by Innovation and Technology Fund (ITF) with title "Exploring the use of Transition Metals and Their Compounds as Catalyst for Cotton Finishing Treatment" (ITS/029/12). Authors would like to thank the financial support by ITF.

\section{REFERENCES}

[1] C. W. M. Yuen, S. K. A. Ku, C. W. Kan, Y. F. Cheng, P. S. R. Choi, and Y. L. Lam, "Using nano- $\mathrm{TiO}_{2}$ as c-catalyst for improving wrinkle-resistant of cotton fabric," Surface Reviews and Letters, vol. 14, pp. 571-575, 2007.

[2] C. C. Wang and C. C. Chen, "Physical properties of crosslinked cellulose catalyzed with nano titanium dioxide," Journal of Applied Polymer Science, vol. 97, pp. 2450-2456, 2005.

[3] C. C. Chen and C. C. Wang, "Crosslinking of cotton cellulose with succinic acid in the presence of titanium dioxide nano-catalyst under UV irradiation," Journal of Sol-gel Science and Technology, vol. 40, pp. 31-38, 2006.

[4] C. C. Wang and C. C. Chen, "Physical properties of the crosslinked cellulose catalyzed with nanotitanium dioxide under UV irradiation and electronic field," Applied Catalysis A: General, vol. 293, pp. 171-179, 2005.

[5] C. X. Wang and Y. P. Qiu, "Two sided modification of wool fabrics by atmospheric pressure plasma jet-influence of processing parameters on plasma penetration," Surface and Coatings Technology, vol. 201, pp. 6273-6277, 2007.

[6] Y. J. Hwang, M. G. Mccord, J. S. An, B. C. Kang, and S. W. Park, "Effects of helium atmospheric pressure plasma treatment on low-stress mechanical properties of polypropylene nonwoven fabrics," Textile Research Journal, vol. 75, pp. 771-778, 2005. 
[7] K. N. Pandiyaraj and V. Selvarajan, "Non-thermal plasma treatment for hydrophilicity improvement of grey cotton fabrics," Journal of Materials Processing Technology, vol. 199, pp. 130-139, 2008.

[8] K. Vaideki, S. Jayakumar, R. Rajendran, and G. Thilagavathi, "Investigation on the effect of RF air plasma and neem leaf extract treatment on the surface modification and antimicrobial activity of cotton fabric," Applied Surface Science, vol. 254, pp. 2472-2478, 2008.

[9] H. U. Poll, U. Schladitz, and S. Schreiter, "Penetration of plasma effects into textile structures," Surface and Coatings Technology, vol 142-144, pp. 489-493, 2001.

[10] C. X. Wang, Y. Liu, H. L. Xu, Y. Ren, and Y. P. Qiu, "Influence of atmospheric pressure plasma treatment time on penetration depth of surface modification into fabric," Applied Surface Science, vol. 254, pp. 2499-2505, 2008.

[11] K. Stephen, "Plasma processes for wide fabric, film and non-wovens," Surface and Coatings Technology, vol. 186, pp. 214-217, 2004.
[12] K. V. Rajpreet and N. R. Gita, "Plasma and antimicrobial treatment of nonwoven fabrics for surgical gowns," Textile Research Journal, vol. 74, pp. 1073-1079, 2004.

[13] N. De Geyter, R. Morent, and C Leys, "Penetration of a dielectric barrier discharge plasma into textile structures at medium pressure," Plasma Sources Science and Technology, vol. 15, pp. 78-84, 2006.

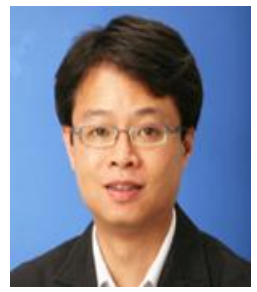

C. W. Kan is an associate professor in the Institute of Textiles and Clothing, The Hong Kong Polytechnic University. Dr. Kan earned his BSc and $\mathrm{PhD}$ in textile chemistry from the Hong Kong Polytechnic University. His research major is in the field of textile coloration and finishing and surface modification of textile materials. Dr. Kan has worked extensively in the field of plasma treatment and has published more than 80 peer-reviewed journal and conference articles in this field. 